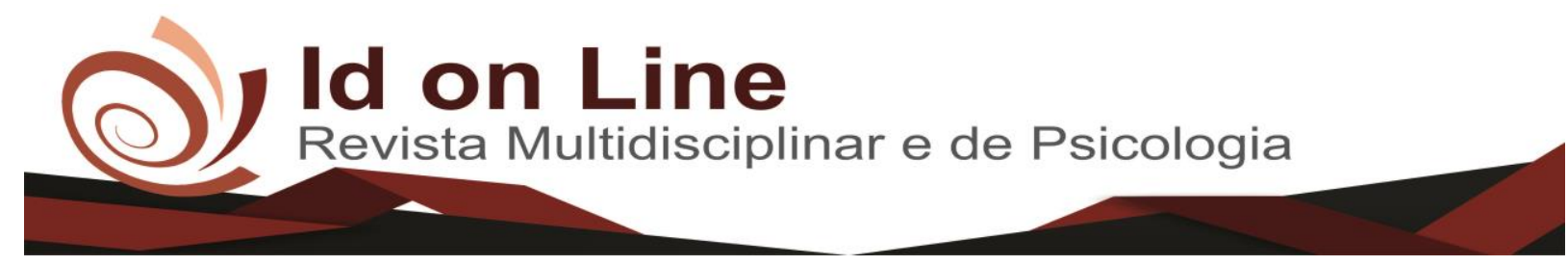

Artigo de Revisão

\title{
Os Sistemas Florestais na Preservação das APP
}

\author{
Fernanda Teixeira Ribeiro ${ }^{\text {; }}$ Mariana Emídio Oliveira Ribeiro ${ }^{2}$; Bianca Inêz Antoniolli ${ }^{3}$; José Marcos Santos da \\ Silva ${ }^{4}$ Edileuza Valeriana de Farias Venturin ${ }^{5}$
}

\begin{abstract}
Resumo: O atual item sobrepuja relatos que podem incidir os códigos florestais na recuperação de Áreas de Preservação Permanente (APP). Nos estudos sobre princípios florestais, múltiplos fatores são aliados, não somente aos pequenos agricultores, mas também para aqueles que possuem nas propriedades áreas que precisam de preservação. Os métodos de estudos que foram compostos pela presente pesquisa bibliográfica qualitativa e exploratória, foram estudos situados nas linguagens dos vários autores citados na mesma. Os objetivos elencados nesse estudo possuem confirmação pelo papel importante do equilíbrio ecológico das propriedades que torna uma opção que pode ser adotada em propriedades que tenham produção da agricultura familiar. Os benefícios dos sistemas florestais, estão na diversidade citar a de espécies utilizadas nas formas de plantio; melhoria e a capacidade produtiva do solo ;reduzido a utilização dos recursos naturais disponíveis; adaptando-se as condições ecológicas que trazem vantagens sutis em curto tempo.
\end{abstract}

Palavras- Chaves: Sistemas Florestais, Preservação de Áreas de Apps, Equilibro Ambiental.

\section{The Forest Systems in the Preservation of APPS}

\begin{abstract}
The present article contain reports that canidentify the forest systemsin the recovery of Permanent Preservation Areas (APPS). The study aboutforest systemsholds several important factors that are allied not only to small farmers, but for those who have in their properties areas that need preservation. The methods of study that were composed by the qualitative and exploratory bibliographic research.Werea study found in the languages of several authors mentioned in the article. The objectives listed in this study were confirmed by the important role of the ecological balanceof the properties that make it an option that can be widely usedin properties that have their form of production classified as family agriculture.As a benefit in the adoption of forest systems, itcan be mentioned the variability of species used in planting models; improving the productive capacity of the land; optimization of the use of available natural resources adapted to the ecological conditions that bring subtle advantages in a short time.
\end{abstract}

Keywords: Forest Systems, Preservation of Apps Areas, Environmental Equilibrium

\footnotetext{
${ }^{1}$ Acadêmica do $8^{\circ}$ semestre do curso de Administração da Faculdade de Alta Floresta FAF.

${ }^{2}$ Professora do curso de Administração da FAF. Professora do curso de Ciências Contábeis da FAF. Professora de ensino técnico e profissionalizante do SECITEC de Alta Floresta-MT. Mestranda do Programa de Pós Graduação em Ambiente e Desenvolvimento PPGAD da Universidade do Vale do Taquari UNIVATES. Especialista em Didática do Ensino Superior. Especialista em Gestão Estratégica de Pessoas. Especialista em Planejamento, Implantação e Gestão do EAD. Graduada em Administração.

${ }^{3}$ Professora do curso de Administração da FAF. Professora do curso de Ciências Contábeis da FAF. Especialista em Didática do Ensino Superior. MBA em Gestão Estratégica de Negócios. MBA em Gestão Estratégica de Pessoas. Contato: mariana_meo@ hotmail.com; ${ }_{4}^{4}$ Possui graduação em Administração de Empresas pela Escola de Administração de Empresas da Bahia 1989, atual UNIFACS. Especialização em Administração Hospitalar pela UFMT, Contabilidade Auditoria e Perícia pela AJES, Especialização em Didática Do Ensino Superior pela UNIFLOR - União das Faculdades de Alta Floresta.

${ }^{5}$ Mestra em Direito pela UNITOLEDO de Araçatuba - SP, Área de Concentração: Prestação Jurisdicional no Estado Democrático de Direito ? Linha de Pesquisa: Tutela Jurisdicional dos Direitos Sociais, Difusos e Coletivos (2012). Pós-Graduada em Processo com ênfase em Didática do Ensino Superior pela UNISUL(2008/2009) Pesquisa: Protagonismo Carcerário. Graduada em Direito pelo Centro Universitário Do Norte Paulista (2002). Coordenadora do Curso de Direito da Faculdade de Direito de Alta Floresta - FADAF 2017.
} 


\section{Introdução}

Diante dos contextos ambientais, os sistemas florestais apresentam-se como qualquer ampla escolha detém a prevenção ambiental, queconvêm debase para a estrutura produtiva de alimentos junto com espécies nativas consórcios com outrasculturasconvencionais. Ademais, hojefala-semuito sobre sustentabilidade, e na prática indaga-se que alternativas e ações estão sendo implantadas, que possam promover o desenvolvimento sustentávelde maneira viável na sociedade.

No entanto, a frente dessa situação não se pode descartar a importância dessas atividades para a sobrevivência dasociedade, isso remetea um desafio de construir tecnologias adequadas à preservação da biodiversidade, com restruturação das áreas degradadas, áreas de preservação, matas ciliares, de acordo com a legislação.

Segundo Carvalho (2008), atualmente vive-se um período de grandes crises, uma delas é a crise ecológica, no qual é uma área que afeta a sociedade, pois, os proveitosadequados estão cada ocasiãoigualmente degradados, escassos e poluídos. Recentemente hámuitas formas de insustentabilidade como modelo de exploração da natureza que a sociedade pratica.

Para Miller Pedroso (2006), o ambientegeográfico consistir emque mais padece com as alteraçõesfalho a colocação humana, já que, a população maior éa urbanaque predomina e enfrenta vários problemas tais como: o desemprego, falta de habitação, poluição entre outros. Porém, uma das atividades que se desenvolve é a agropecuária, demodo devastadora constituiatuação de desmatamentos caóticosempregandochama, ocasionando incêndios e por consequências destruindo florestas, diminui fauna e flora, contamina nascentes e empobrece o solo.

Segundo Castro (1996), os sistemas agroflorestais (SAF`s), são reconhecidos como modelos que oprimem osterrenosde maneira econômica se beiram da mata espessa natural, compondo assim, hígido, determinados quanto ao modo sustentável de estimação da aplicação de Códigos florestais. É também evidente quando se conclui a existência de extensas áreas desprovidas em decorrência a deterioração, resultada técnica do plantioexcessivo, reconhecida como uma usodos solos de maneira nãosustentável.

Os sistemas florestais têm como propósito, a concepçãode múltiplas plantas, tendo em vista, imitar um bosque natural. Nos princípiosflorestais asárvore, arbustos, carecido a extensão que desempenham ação de reciclagem de nutritivos e no rendimento da energia solar 
são vistos como elementos estruturais básicos, que dá a estabilidade nos sistemas implantados (OLIVEIRA et al., 2011).

Estas matas comprovam escolhas por garantirem o cultivo diferençada e continua ao longo dos anos, sem deteriorar o solo contornarqualqueradequadoexemplo agrícola, próspero nocasamentodentrecultivo e conservação ambiental, trazendo grandes benefícios para o setor rural.

Nesse sentido, o atual trabalho apresenta por escopo identificar como as instruções florestais que operam na cobrança das extensões de prevenção constante. Sendo que os objetivos específicos é verificar os benefícios que estes sistemas ocasionam no cuidado das APPS e diagnosticar os avanços no conjunto dos princípios florestais. Tendo como problema a viabilidade de implantação dos Safs.

Com o intuito de levar informações que venham contribuir para o meio acadêmico, usufruindo de pesquisa embasadas em obras literárias, sendo explorados por todos. Diante disso, levar informações adquiridas sobre o meio ambiente têm uma importância consolidada em todos os meios que se encontram, pois, o bem-estar social e ambiental são de grande importância para todos.

\section{Metodologia}

A metodologia foi realizada para identificar de que maneira as áreas de preservação constantesão readquiridas pelos sistemas florestais, transversalmente de análises bibliográficas, artigos científicos e sites especializados. Oartifícioempregado para a indagaçãoconstituirá noprocedimento indutivo.

Segundo Lakatos (2010, p.166), a análise bibliográfica, ou de fontes secundarias, compreende toda literatura já tornada inegável em inclusão ao assunto de esboço, deperiódicosisoladas, revistas, circulares, obras, análises, dissertações, assuntos, material cartográfico etc., até mesmoelementos de difusãoverbal: rádio, gravações em faixa magnética e audiovisuais. Para pesquisa bibliográfica foi composta em livros, revistas, periódicos e materiais como artigos referentes ao assunto proposto. 
Lakatos explica que o procedimentoindutivo advém à generalização pelo qual passa de um caso particular para um caso universal. A Inferência é um técnicaintelectual por intercessão do qual confinando elementos privados, satisfatoriamente averiguados, levar uma veracidade unânime ou ecumênica, não contida nos componentesanalisadas. Assim, o objetivo dos argumentos indutivos é levar a conclusões, cujo conteúdo é muito mais amplo do que o das premissas nas quais se basearam (LAKATOS, 2007, p.68).

No entanto, a pesquisa exploratória qualitativa abrange formulação de litígios ou de umadificuldade com intuito de estudar os fatos como: ampliar hipóteses, adicionar a contubérnio do analisador com o ambiente, acontecimento ou fato, para efetivação de uma análise futura mais necessita ou decompor e qualificaropiniões (LAKATOS,2007, p.171).

\section{Referencial Teórico}

O termo agro florestal é uma prática bastante antiga que era usada pelos indígenas,compreender os Saf's como sistemas sustentáveis de uso da terra, é preciso adaptar de maneira simultânea, a realidade de cultivos agrícolas comoplantações de espécies frutíferas,florestais entre outras espécies, pois, traz valor econômico e ecológico presente na região, que utiliza-se a mesma quantidade de terra e aplica-se astécnicas de manejo que são adaptáveis com as práticas culturais (KING; CHANDER, 1978).

As Áreas de Preservação Permanente -APPs, são áreas amparadas nos arts. $2^{\circ}$ e $3^{\circ}$ daEnsino Florestal. O termo de APP relaciona tais áreas, dependente de sua cobertura e função ambiental usada para preservar recursos hídricos, fauna e flora, a proteção do solo paragarantir o conforto das populações afetuosas (VIÇOSA ,2005).

Os princípiosflorestais apresentam como desígnio inicial a criação de vários estratos vegetais, que visa imitar um bosque natural. Noentanto, os sistemas florestais, asárvores, e outras vegetações, sofrem influência no processo de ciclagem dos nutrientes e aproveitam da energia solar para se estruturar, tendo paraduração do princípio (OLIVEIRA et al.,2011).

Sãoacrescidosespecialmente nas regiões ardentes e subtropicais, pois caracterizam pela mistura de árvores em diversos campos, visto que, oferece vários fatores a partir das interações ecológicas e poupadas que desenvolvem com esse processo (MILLER; PEDROSO, 2006). 
Ayres e Ribeiro (2010), demonstram que os sistemas agroflorestais são ideias por apresentarem vantagens e abonarem em um cultivo diversificado e consecutivo ao longo dos anos, sem deteriorar a produção agrícola e conservação ambiental.

Os benefícios atribuídos são consolidados na adoção de práticas florestais, sua importância está na cobertura do solo e aumentaos teores orgânicos da matéria; traz relevante ciclagem dos nutrientes; controla a erosão; reduz a adubação com insumo químicos, e aumenta a utilização de orgânicos, abandonandoos agrotóxicos (ALVES, 2009).

Os princípios agroecológicos tornabons em recuperação de áreas degradadas. Além de serem uma opção na recuperação de áreas, ajudam na renda dos agricultores, o incremento de um preceito florestal, é algo que exige trabalho por parte dos agricultores, depois de certo tempo, em fatores de mão de obra, analisa que, o trabalho é menor, do que na agricultura consagrada (FÁVERO; LOVO; MENDONÇA, 2008).

Os sistemas florestais constituem-se viável para o uso da terra, além do rendimento favorável que admiteacrescentar ocultivoabsoluto de maneira maior, por meio da introdução de bosques com cultivos de agricultorese criações de animais, isso aplicaas práticas dos manejos compatíveis com padrões culturais da população (MACEDO, 2000).

Além disso, quintais e pomares familiares comum, constituem em um ótimo e mais antigo exemplo de sistemas florestais, compostosde feitio casual, sem acomodação, visa para família o mantimentode frutas, com a preocupação de fundo econômico e ecológico. E claro a combinação de qualidades perenes, classes temporárias (DANTAS, 1994).

Montoya; Mazuchowski (1994), comenta que, em suas perspectivas os benefícios desses sistemas estão no cultivo e colheita alimentos. Além disso, á outros serviços de preservação do solo, que aumentam a fertilidade, pois usam restabelecimento de nutrientes, os sistemas florestais apresentam ruma a sustentabilidade (MONTOYA; MAZUCHOWSKI, 1994).

Porque ainda que, suas potencialidades sejam importantes na recuperação de fragmentos, podesalientar a restauração de eco unidades degradadas, corredores, recuperação de matas reservas e manejo florestais implantados (AMADOR; VIANA, 1998).

Santos et al (2000), recomendam o uso de sistemas florestais para restauração de paisagens fragmentadas, na forma de garantir a existência mínimaentre as remanescentes quanto a vegetação natural, entre viabilizar a conservação de uma biodiversidade relativa e rica de produtos. 
Os sistemas florestais são recomendados como princípiosamparáveis e expostos como uma escolha para a recobramentode áreas desedificadas, pois contribuem na reconstrução dos solo pois fazem a recuperação da paisagem florestal, envolvendo todos os recursos naturais, tais como: agua, solo e ar faz sistemasdemonstram que, é preciso recompor a os nutrientesno solo, não somente na superfície mas, nas camadas inferiores; fixação de nitrogênio, reduz as erosões e ajudam aumentar matéria orgânica (DANIEL ET AL, 1999).

Valeri e Menezes (2000), comentam a potencialidade do uso dos sistemas florestais como alternativa da recuperação da biodiversidade e falhas florestais das áreas de preservação onde é necessário incentivar os componentes de reservas florestais. Orienta ainda, que nosprimários anos da locação dessas extensõesestejamcuidadas, o cultivo das classes arbóreas, tradições de estabilidade, de sementes criolas, essas culturas cubra os gastos dos reflorestamentosimplantados.

As práticas de sistemas florestais intervêm e podem ser executadas em várias maneiras. Por exemplo, nos roçados e nas pastagens existem em geral árvores primarias de sementes ou de rebentos de troncos. Tais espécies são utilizadas pelos proprietários, para uso local, ou para a venda. E são práticas recomendáveis na regeneração natural a crescer e formar frutos de qualidade. Assim não exige muita mão-de-obra e ajuda a formar áreas cultiváveis (VALERI E MENEZES,2000).

Ademais, os sistemas florestais podem terdiversas diversificação em pastos e culturas, pois auxiliam na vegetação de ambiente degradadas, e trazem adubação verde, produz matriz energética na capitação dos biocombustíveis (SANTOS, 2000).

Além de economicamente viável, esses sistemas são benéficos para recuperar com introdução de diversas espécies defendidas pelo autor, entre elas as madeiras de proteção legal tais mogno, castanha-do-brasil entre outras se enquadra as de produção de frutos diversos tipos de mangas, pitangas, cupuaçu e com cultivo de leguminosas nos aos inicias. Os sistemas florestais fornece variedades em produção, gera maneiras de obter renda para os agricultores e ajuda a diminuir danos em safras. Além, da diversidade de espécies implantadas nesse sistema, a também o trabalho mutuo que ocupa as famílias, estimulando o desenvolvimento dos sistemas florestais e aumentando os seus efeitos(SANTOS,2000).

Embrapa (2011), faz referência entre integração e interação dos componentes pecuários, agrícola, expondo vital importância para o desenvolvimento sustentável com 
sistemas florestais. Relaciona os impactos no meio ambiente e a máxima biodiversidade possível, o uso em conservar o solo, a produção e preservação da água.

Os sistemas florestais construí opção interessante e viável para oferta simultânea de mantimentos e outros bens, podendo ser inseridos eaproveitados em terras já tomadas com princípios de monocultivos, seja agrícola e florestal. Para o produtor florestal as básicasregaliasé o desconto do custo fixaçãode reposição, embora pequena, a proteção florestal devastada pelo progresso da demarcação agrícola. Desta forma, os sistemas florestais estabelecem numa escolha conveniente, apesar queestejaminsuficientes as informaçõesa respeito dautilização atual e o potencial da mesma, o que tem dificultado sua propagação pela expansão rural (MEDRADO, 2000).

A introdução dos componentes florestais nas lavouras tem um enfoque que precise separar agricultura, pecuária e floresta, porem utilizar seus componentes em benefícios dos mesmos, aumentado a qualidade de vida, subsidiando a sustentabilidade e permitindo as melhorias nas práticas florestais das propriedades (VANDERLEY PORFÍRIO,2004).

O cultivo emplantações e pastoscompõena reposição da cobertura florestal, embora pequenas dizimadas pelo avanço da fronteira agrícola. Desta forma, os sistemas florestais mantêm a qualidade de vida dos solos crescente, a utilização atual e o potencial das mesmas, pode dificultar a fusão nas extensões rurais (MEDRADO, 2000).

Segundo Dúbios (1996), sistemas florestais podem contribuir na melhoria alimentícias das populações rurais. Um quintal florestal de tamanho suficiente e constituído por um número de espécies, pode fornecer uma parte dos alimentos consumidos pelos agricultores. Por outro lado, determinados sistemas florestais, como as capoeiras melhoradas de longa duração atraem alimentos. Facilitando omanejo e seu aproveitamento para fins de existência. Do mesmo modo, que os sistemas florestais ajuda a manter a capacidade produtiva da terra, as árvores adubam o solo melhorando a estrutura física.

Uma das maiores vantagens dos sistemas florestais é sua capacidade de manter sua produção em longo prazo e trazer melhoriasde forma sustentável (CASTRO et al,1996).

Vantagem esta que, muitas espécies de árvores e arbustos utilizados nos sistemas florestais tem e outras funções, adubar, proteger e conservar a fertilidade do solo. Estes sistemas quase sempre manejados sem aplicação de agrotóxicos sobre o meio ambiente portanto são mínimos. Outro aspecto importante é que associa árvores e arbustos em culturas 
agrícolas e também em pastagens, contribuemna melhoriasde rios entre vertedouros d'água (MEDRADO, 2000).

A característica mais importante dos sistemas florestais parece ser a força ecológica, que se apoia na sustentabilidade, aumentando a estabilidade, que implica em desigualdade biológica com alocação de inúmeras espécies para garantir a estabilidade ecológica e econômica. A estabilidade é confiável pelas distintas opções de cultivo e mercado, pelo desenvolvimento das várias culturas. Tornando os sistemas florestais sustentáveis pela habilidade em manter a produtividade (DANTAS,1994).

Os sistemas florestais são conhecidos por ter um método agrícola que fornece ouso sustentável no desenvolvimento, apresentapontos positivo e negativos que relevam em grau os aspectos sociais, econômicos, culturais e ambientais (DANIEL et al,1999).

Entre os pontos positivos e negativos dos modelos florestais, descreve-se: Biológicas, Físicas e Ambientais. Ainda outras melhorias apontadas propriedades nas condições: químicas, físicas e biológicas, isso acrescenta o cultivo e produção; pois há o controle da erosão; baixas microclimáticas; controle de perda de produção; apoio para trepadeiras; modoapropriado do assombramento em todas as plantas (FERNANDES et al,1994).

Proveitos económicas e Sociais: ampliação do ganho dos agricultores rurais; maior abundância de produtos e ocupações; progresso no nutrimento do ente do campo; diminuição de riscos de insucesso; redução das despesas no plantio; avanço na repartição de mão-de-obra; desconto das obrigações(DANTAS,1994).

Avanço na concorrência entre os elementos vegetais; aceitável lesão de nutrientes; tortosreflexos durante a ceifa ou corretagens culturais; agravoselevados pelo artifícioanimalesco; alopatia; habitat, hospedeiros para insetos e doenças; problema de mecanização; enigma no projeto(MACEDO,2000).

Para Ribaski (2012) Eles promovembenefícios dede, melhoria da subsistência na renda dos agricultores que, os mesmos podem usufrui das condições econômicas, ecológicas e sociais que favorece o desenvolvimento sustentável.

É possível alinhar espéciesde força econômica sendo, hortaliças, leguminosas as que produzem frutos. Pois as variedades de leguminosas pode ser usada para adubação verde, esse processo se dá pelo corte fazendo a reposição de nutrientes no solo (EMBRAPA, 2004). 
As influências dos sistemas florestais se justificampelas necessidades de associar a produção agropecuária aos serviços ambientais, o sequestro de carbono, a qualidade da água, conservação do solo, dinamização da erosão, o equilibro da biodiversidade dos princípiosfecundosaproximar-se a encorajar o desenvolvimento socioeconômico, às questões de proteção ambiental assim ajudando a desenvolver multiplicar as áreas de preservação permanentes (EMBRAPA, 2004).

Aampladiferença de qualidadesde plantas cria-secategoriasadeptas para a consignação das colocações ecológicas nas propriedades isso faz que, os agricultores fiquem em suas propriedades e produzem cada vez mais (DE PAULA, 2003).

Ressalta-se também a contribuição para a defesa do meio ambiente, recursos naturais, promovendo assim o rapto de carbono e o acréscimo da biodiversidade, seja da produção animal ou de plantas frutíferas. As regrasflorestais é daveemência dos cultivadores, pois, permanecem aliados àcultivo de alimentos, por oferecem produtos de origem agrícolas e florestais, desenvolvendo a valorização dosgrupos (EMBRAPA, 2004).

Os sistemas florestais têm opções agroecológicas do uso e demonstram várias vantagens que superam os riscos em seu processo, no que, se refere os principais componentes. Oferecem também diversidade de produtos, gerando várias fontes de renda para os produtoresem quefornecemdetémem reduzir os prejuízos com as safras (DANIEL et al,1999).

Montoya (1999), comenta que os benefícios econômicos e ambientais se mantem a em períodos longos, porem as espécies produzem mais atinge valores de comércio pois demonstram quantidades significativas já no terceiro ano de sua implantação.

\section{Resultados e Discussões dos Dados}

\section{A Viabilidade de Implantação dos Sistemas agroflorestais}

Valeri e Menezes (2000), comentam que, uso dos sistemas florestais como alternativa da recuperação da biodiversidade e falhas florestais das áreas de preservação onde é necessário incentivar os componentes de reservas florestais. Orienta ainda, que nos primeiros anos da implantação dessas áreas sejam cultivadas, o plantio das espécies arbóreas, culturas 
de subsistência, como o milho, soja, feijão e mandioca, de maneira que essas culturas cubra os gastos dos reflorestamentos implantados.

A demora para o retorno financeiro pode prejudicar o produtor como comenta o autor, pode ser a médiocomenta que os benefícios econômicos e ambientais se mantem a em períodos longos, porem as espécies produzem mais atinge valores de comércio pois demonstram quantidades significativas já no terceiro ano de sua implantação. (MONTOYA, 1999).

\section{Como os Sistemas Florestais Atuam na Recuperação das Áreas de Preservação Permanente}

Atuam de forma bastante eficiente, assim foi que originou o termo agroflorestal, cuja prática é muito antiga, qual foi utilizada pelos indígenas. Porém, para entender e conceituar os Saf's como sistemas sustentáveis de uso da terra, é preciso adaptar de maneira simultânea, pois a realização de cultivos agrícolas e espécies florestais, traz valor econômico e ecológico presente na região, onde utilizam-se a mesma quantidade de terra e se aplicam as técnicas de manejo que são adaptáveis com as práticas culturais (KING; CHANDER, 1978).

Assim, contribui-se para preservação do meio ambiente, solo, recursos hídricos, promove o a retenção de carbono e, aumenta a biodiversidade, além do cultivo animais e de plantas frutíferas. Uma contribuição a mais ao meio ambiente (EMBRAPA, 2004).

\section{Os Benefícios dos Sistemas Florestais na Preservação das APPS}

Os sistemas florestais são bons e tem pontos positivos que mantem uma produção diversificada e contínua ao longo dos anos, sem deteriorar o solo sendo, um exemploagrário e próspero na aliança entre plantioda agricultora e amparo ambiental (AYRES E RIBEIRO, 2010).

Dúbios (1996) esclarece que, sistemas florestaismelhora a alimentação dos agricultores e suas famílias. Nos quintais florestais, eles descobrem a oportunidade de desenvolver e fornecer em maioria alimentos que são consumidos pela sociedade. Em alguns 
sistemas florestais de longa duração, colhem diversos tipos de cultivo que pode abastecer e agregar ainda mais melhoria dentro das comunidades rurais mais de toda população.

Do mesmo modo que os sistemas agroflorestais ajudam a manter a condição da produção e suas fertilidades, pois os mesmos produzem adubo orgânico e melhoram solo (DÚBIOS ,1996).

\section{As Influências dos Sistemas Florestais na Sociedade}

Viçosa (2005) explica que, áreas de preservação permanente são extensões resguardadas nas adjacências dos arts. $2^{\circ}$ e $3^{\circ}$ do Código Florestal. O julgamento legalístico inclui tais áreas, autônoma da touca vegetal, com a colocação ambiental de conservar os recursos hídricos, a paisagem, a permanência da biodiversidade, o andamento a fauna e flora, resguardar o solo e garantir as comodidades humanas (VIÇOSA,2005).

Os Sistemas florestais se constituíramprimeiramenteem aldeiasaborígines. Ultimamentehígidoe adequados de várias maneiras. Ademais, são caracterizados pela admissão e combinação de árvores, arbustos em áreas agrícola, pecuária, propiciando benefícios ecológicas e econômicas que se desenvolvem nesse período (MILLER; PEDROSO, 2006).

Segundo Umrani (2010), os sistemas florestais nãofornecem nichos e habitats que os ecossistemas originais, mais devem ser promovidos em harmonia da vegetação nativa remanescente, sendo um importante mecanismo complementar em esforços de preservação de amplas espécies dentro da propriedade.

Vieira et al. (2009), comentam que, os benefíciosdas áreas de Apps por estender em período de manejo da restauração que possibilite a introdução de espécies no momento mais propícios, isso reduz e compensa os gastos no processo, proporciona qualidade alimentar para os pequenos produtores e os envolvem no processo de restauração.

Sistemas florestais apresentam pontos positivos por fornecerem diversificada produção, sem detorar os solos, sendo, a maneira agrícola que permite um alicerce entre produção agrícola e a proteção ambiental (AYRES E RIBEIRO,2010). 
Entre benefícios à adoção de práticas dos sistemas florestais, destaca-se: oapego na cobertura do terreno e acréscimo nos princípios orgânico; força dos nutrientes; domínio de erosão; adubação com foco no desconto no uso de fertilizantes (ALVES, 2009).

De acordo com Iwataet al. (2012), os efeitos dos sistemas florestais sobre o solo, constituem a promoção maior em teores de nutrientes, garantindo uma melhoria da qualidade química do solo entre outros.

Atualmente estamos em um período que os bens naturais estão mais insuficientes desedificados e corrompidos. Nos anos atuaisapresentamcomprovaçõesindiscutíveis da insustentabilidade do exemplo de opressão da naturalcometido pela ação do homem. Porém, é preciso considerar que muito atualmente os sistemas florestais mostram o desenvolvimento sustentáveis que muitos procuravam (CARVALHO, 2008).

Os sistemas florestais é a forma de usar oterreno no qual se convencionamcondições de estarem cultivadas de forma agrícolas sem separar de animálias, de feitio simultânea ou em encadeamentoatenuado e que interagem econômica e ecologicamente. Além do mais, que este aspecto que determina a sustentabilidade desses sistemas é a presença das árvoresque capturara nutrientes em camadas do solo, reciclando-os eficientemente e proporcionando maior cobertura e conservação dos recursos edáfico. (EMBRAPA,2011).

Adotar os sistemas florestais justifica que, é possível juntara produção agrícola com os serviços ambientais, pois auxiliam na qualidade de vida do meio ambiente, pois, melhora as nascentes de águas, conserva os solos, minimiza as várias erosões (EMBRAPA, 2004).

Os sistemas florestais da a essência florestal segue apreciações atuais de usos de reflorestamento sob questão econômica, agrega valores as espécies arbóreas de modo quetodo modelo sege acrescido.Visto que se discute um princípio com imobilização de soluções por um longo prazo é indispensável que todo aidealização envolvido seja desde o arranjo do terrenodetém os simplescultivos até a transação do produto, ou seja, a madeira e que tudo constitua disponibilidade de produtos variáveis e com o antecedenteinformação dos folhososdesde produtos de ajuste com as particularizações do negócio (SOUZA et al., 2007).

As florestasapresentamgrandes novidades e opções que visam o desenvolvimento socioeconômico do país e troquemparaplantio migratória, desse formato, figuraspeculiares sobre a viabilidade parcimoniosadesdeaquisição em sistemas florestais como escolha para a diversificação docultivo e renda, e cobrança ambiental nessas terras têm sido cada vez mais necessários (BENTES GAMA ET AL., 2005) 
Os fundamentais modos e proveitos dos princípios florestais, destaca, esses sistemas enquanto alternativa detém recomposição e modo sustentável das restriçõeslegalísticas e ressalta que esses sistemas são uma alternativa viável. A princípio esses sistemas são por demasiadoproveitosos nasdimensões ecológica, ambiental assim comoconferido aos sistemas convencionais, tornam-se melhores (Martins ,2013).

Scales e Marsden (2008), ao revisarem quarenta e três análises que compararam, evidenciaram a riqueza e a diversidade de espécies que os sistemas florestais podem conter, então concluíram que trinta e quatro estudos apontavam menor riqueza de espécies nas florestas. A eficácia das estratégias que forma aprodução e conservação, é controversa mais se torna precisa. Portanto, a perspectiva de proteção da biodiversidade destruída é regatada pelossistemas agroflorestais e apontam que a não há classificação de áreas para produção, com rendimento maior ou menor, distintas de proteção dos habitats naturais.

\section{Considerações Finais}

Em suma, os sistemas florestais são vistos como um ponto positivo. Na maioria das vezes, as árvores servem como manancial de renda, já que sua matéria prima é usada e, os produtos das mesmas podem ser empreendidos e revendidos. As combinações desses fatores tornam os sistemas florestais um modelo de agricultura sustentável. Além do mais, os sistemas florestais devem ser incentivados. Visto que suas vantagens superam as desvantagens. Já que se trata de uma proposta benéfica no recobramento de extensões degradadas, já queajuda nos manejos, recompõem as áreas que necessitam de cuidados e demais áreas que aparecerem e no estabelecimento, já que se fará o emprego de espécies, leguminosas e fixadoras de nutrientes, frutíferas e arbóreas detémacabamentosno cultivo de madeira para consumo.

É um sistema com grande diversidade de espécies vegetais, busca criar condições favoráveis para o melhoramento das funções ecológicas e ambientais na propriedade permitindo também, comodidade e segurança aos produtores.

Os autores citados nesse artigo, por finalidade de pesquisa afirmam que os sistemas florestais contribuem para qualquerampliação econômicaalém disso, é sustentável e inferiormentehostil ao elemento ambiental. 
Esse estudo teve a finalidadede demonstrar informações que puderam confirmar que os sistemas florestais são formas ecológicas e correta, socialmente aceitável e de custo baixo aos produtores rurais, no sentido de inovar com tecnologias capazes de suprir o possível das condições originárias detém a ampliação da conservação e preservação dos ciclos ambientais da capacidade das áreas de APPS.

\section{Referências}

ALVES, A. M. S. Sistemas agroflorestais, transformações na agricultura e o desenvolvimento local sustentável. História \& Perspectivas, Uberlândia (41): 33-58, jul.dez.2009.

AMADOR, D. B.; VIANA, V. M. Sistemas agroflorestais para recuperação de Fragmentos florestais. Série Técnica. IPEF, Piracicaba, v. 12, n.32, p. 105-110, 1998.

AYRES, E. C. B.; RIBEIRO, A. E. M. Inovações agroecológicas no Nordeste de Minas Gerais: o caso dos sistemas agroflorestais na agricultura familiar do alto Jequitinhonha. Organizações Rurais \& Agroindustriais, Lavras, v. 12, n. 3, p. 344-354, 2010.

BENTES-GAMA, M. M., SILVA, M. L., VILCAHUAMÁN, L. J. M., LOCATELLI, M.Análise Econômica de Sistemas Agroflorestais na Amazônia Ocidental, Machadinho D’oeste- RO. R. Árvore, v.29, n.3, p.401-411. Viçosa, 2005.

CASTRO, C. R. T.; LEITE, H. G.; COUTO, L. Sistemas Silvia Pastoris:potencialidade entraves. Revista Árvore, Viçosa, v.20, n.4, p.575-582, 1996.

CARVALHO, P. E. R. Espécies arbóreas de usos múltiplos na região sul do Brasil. In: CONGRESSO BRASILEIRO SOBRE ECOSSISTEMAS AGROFLORESTAIS, L, 1994, Porto Velho. Anais..., Colombo: Embrapa-CNPF, 2008. p.289-320.

DANIEL, O.; COUTO, L.; SILVA, E. et al. Sustentabilidade em sistemas agroflorestais: indicadores biofísicos. Revista Árvore, Viçosa, v.23, n.4, p.381-392, 1999.

DANIEL, O; COUTO, L.; GARCIA, R. et al. Proposta para padronização da terminologia empregada em sistemas agroflorestais no Brasil. Revista Árvore, Viçosa, v.23, n.3, p.367$370,1999$.

DE PAULA, C. R., DE PAULA, F. N. Manejo e recuperação florestal. Jaboticabal: Funep. 2003, 180p. 
DANTAS, M. Aspectos ambientais dos sistemas agroflorestais. In: CONGRESSO BRASILEIRO SOBRE ECOSSISTEMAS AGROFLORESTAIS, 1. 1994, Porto Velho. Anais... Colombo: Embrapa-CNPF, 1994. p.433-453.

DUBOIS, Jean. C. L Virgílio Mauricio Viana, Anthony B. Anderson. - Manual agroflorestal para a Amazônia. Volume 1, Rio de Janeiro: Rebraf 1996. p:9, 20, 73 a 77.

EMBRAPA. Sistemas agroflorestais (Saf's). 2004. Disponível em: https://www.embrapa.br/busca-de-produtos-processos-e-servicos/-/produto servico/112/sistemas-agroflorestais-safs. Acesso em: 06 junho. 2017.

Experiência em sistemas agroflorestais. Disponível em < http://www.embrapa.br/imprensa/noticias/2017/junho/foldernoticia.2017-acesso 10 de março CE 2017.

FÁVERO, C.; LOVO, I. C. MENDONÇA, E. S. 2008 Recuperação de área degradada com sistema agroflorestal no Vale do Rio Doce, Minas Gerais. Revista Arvore v. 32(5) 861$868 \mathrm{p}$.

FERNANDES, E. C. M.; MATOS, J. C. S.; ARCO-VERDE, M. F.; LUDEWIGS, T. Estratégias agroflorestais para redução das limitações químicas do solo para produção de fibra e alimento na Amazônia Ocidental. In: CONGRESSO BRASILEIRO SOBRE ECOSSISTEMAS AGROFLORESTAIS, 1. 1994, Porto Velho

IWATA, B. F. et al. Sistemas agroflorestais e seus efeitos sobre os atributos químicos em argissolo vermelho amarelo do cerrado piauiense. Revista Brasileira de Engenharia Agrícola e Ambiental. v.16, n.7, p.730-738, 2012. Campina Grande, PB, UAEA/UFCG. Disponível em:<http://www.agriambi.com.br>. Acesso em: 02 mar. 2017.

KING, K. F. e CHANDLER, N. T. 1978. The wasted lands: The program of work of the International Council for Research in Agro forestry (ICRAF). Nairobi, Kenya.

MACEDO, R. L. G.; VENTURIN, N.; TSUKAMOTO FILHO, A. A. 2000. Princípios básicos para o manejo sustentável de sistemas agroflorestais.Lavras:UFLA/FAEPE.

MACEDO, R. L. G.; VENTURIN, N.; TSUKAMOTO FILHO, A. A. 2000. Princípios de agrossilvicultura como subsídio do manejo sustentável. Informe Agropecuário. v.21 (202) 93-98p

MARCONI, Marina de Andrade e LAKATOS, Eva Maria. Fundamentos da Metodologia Científica. $7^{\circ}$ edição, editora, Atlas S.A São Paulo 2010.

MARTINS, T. P. Sistemas Agroflorestais Como Alternativa Para Recomposição e Uso Sustentável das Reservas Legais. Dissertação Apresentada ao Programa de Pós-Graduação em Ciências da Engenharia Ambiental. São Carlos, 2013 
MEDRADO, M. J. S. Sistemas agroflorestais: aspectos básicos e indicações.Brasília 2000 In: GALVÃO, A. P. M. (Org.). Reflorestamento de propriedades rurais para fins produtivos e ambientais: um guia para ações municipais e regionais.

MILLER, R. P.; PEDROSO, M. S. C. O estado da arte de sistemas agroflorestais na região Centro-Oeste: Cerrado e Portal da Amazônia. In: A.C. Gama Rodrigues, et al. (Org.). Sistemas agroflorestais: bases científicas para o desenvolvimento sustentável. Campos dos Goytacazes: Universidade Estadual do Norte Fluminense Darcy Ribeiro, 2006, v. 1, p. 4352 .

MONTOYA, L.J.; MAZUCHOWSKI, J. Z. Estado da arte do sistema agroflorestal na região sul do Brasil. CONGRESSO BRASILEIRO SOBRE ECOSSISTEMAS AGROFLORESTAIS.1994, Porto Velho. Anais... Colombo: Embrapa-CNPF, 1994. P.77-96. (Documentos, 27).

MONTOYA, L.J.; Estado da arte do sistema agroflorestal na região sul do Brasil. Porto Velho. Anais... Colombo: Embrapa-CNPF, 1994. P.77-96. (Documentos, 27).

OLIVEIRA, R. M. et al. Importância do sistema agroflorestal cabruca para a conservação florestal da região cacaueira, sul da Bahia, Brasil. Revista Geográfica de América Central Número Especial EGAL, 2011- Costa Rica II Semestre 2011 pp. 1-12

RIBASKI, J.; RADOMSKI, M. I.; RIBASKI, S. A. G. Potencialidade dos sistemas silvipastoris para a produção animal sustentável no Brasil. In: II CONGRESO COLOMBIANO Y 1er Seminário internacional de silvopastoreo, 2012, medellin. Congresso colombiano y 1er seminário internacional de silvopastoreo. Medelin, 2012.

SANTOS, M. J. C. 2000. Avaliação econômica de quatro modelos agroflorestais em áreas degradadas por pastagens na Amazônia ocidental. Piracicaba: ESALQ-USP, 75

SANTOS, M. J. C., PAIVA, S. N. Os Sistemas Agroflorestais como Alternativa Econômica em Pequenas Propriedades Rurais: Estudo de Caso. Ciência Florestal, v. 12, n. 1, p. 135-141. Santa Maria, 2000 p. (Dissertação de mestrado).

SILVA, P. P. V. 2002 Sistemas agroflorestais para recuperação de matas ciliares em Piracicaba, SP. ESALQ: Piracicaba. Dissertação (mestrado).

SCALES, B. R.; MARSDEN, S. J. Biodiversity in small-scale tropical agroforests: a review of speciesrichness and abundance shifts and the factors influencingthem. Environmental Conservation, v. 35, n. 2, p. 160-172, 2008.

UMRANI, R.; JAIN, C. K. Agroforestry Systems and Practices. Jaipur: Oxford Book Company, 2010.

SOUZA, A. N., OLIVEIRA, A. D., SCOLFORO, J. R. S., REZENDE, J. L. P., MELLO, J. M. Viabilidade Econômica de um Sistema Agroflorestal. Cerne, v. 13, n. 1, p. 96-106. LavrasVanderley, P. Sistema silvipastoris, Disponível em < 
http://www.cnpf.embrapa.br/pesquisa/safs/index.htm> acesso em 03 de Março de 2017, publicado em 2017.

VALERI, S. V.; MENEZES, J. M. T. Biodiversidade e potencialidade de sistemas agroflorestais na região de Jaboticabal, Estado de São Paulo. In: CONGRESSO BRASILEIRO DE ECOSSISTEMAS AGROFLORESTAIS: Manejando a biodiversidade e compondo a paisagem rural, 3-, 2000, Manaus. Resumos Expandidos..., Manaus: EmbrapaAmazônia Ocidental, 2000. p.63-65. (Documentos, 7).

VIEIRA, D. L. M.; HOLL, K. D.; PENEIREIRO, F. M. Agro-SuccessfulRestoration as a StrategytoFacilitate Tropical Forest Recovery. RestorationEcology, v. 17, n. 4, p. 451-459, 2009.

\section{Como citar este artigo (Formato ABNT):}

RIBEIRO, Fernanda T.; RIBEIRO, Mariana Emídio O.; ANTONIOLLI, Bianca Inêz; SILVA, José Marcos S. da; VENTURIN, Edileuza Valeriana de F. Os Sistemas Florestais na Preservação das APP. Id on Line Revista ultidisciplinar e de Psicologia, 2017, vol.12, n.39, p.300-316. ISSN: 19811179 .

Recebido: 05.12.2017

Aceito: 07.12.2017 